\title{
CIDADE VIRTUAL: NOVOS CENÁRIOS DA COMUNICAÇÃ̃'
}

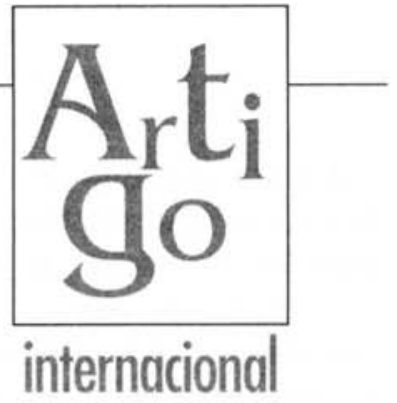

O espaço público da cidade se desintegra, o fluxo, a fragmentação, a reclusão doméstica e a comunicacão, mediada pela televisão e pelas novas tecnologias, reconfiguram hábitos e culturas, criando diferentes sociabilidades

"O próprio da cidade é seu avanço voraz, seu não reconhecimento de fronteiras, seu esquecimento sistemático das tradições. $O$ urbano é, agora, o dom de harmonizar o oposto, o irreconhecível, o duro, o frágil, o marcado pelas generalizações, o que em si mesmo começa e se acaba".

Carlos Monsivais

A cidade nos desafia. Pensá-la, hoje, é assumir uma experiência de des-ordem e opacidade que resiste à olhada monoteísta, omnicompreensiva e nos exige um pensamento nômade e plural, capaz de burlar as divisões das disciplinas e integrar dimensões e perspectivas até agora obstinadamente separadas. Por isso torna-se indispensável tratar da possibilidade de uma olhada de conjunto da cidade, de sua cumplicidade nostálgica com a idéia de unidade ou identidade perdida, as quais conduzem a um pessimismo culturalista que nos está impedindo de compreender de que estão feitas as fraturas que a trincam. Pois esse estalido fala dos novos modos de estar juntos, do modo que os cidadãos experimentam a heterogênea trama sociocultural da cidade, das renovadas formas de exclusão social junto à enorme diversidade de estilos de viver, de mo- dos de habitar, de estruturas do sentir e do narrar. Uma trama cultural que desafia nossas noções de cultura e de cidade, os marcos de referência e compreensão forjados sobre a base de identidades nítidas, de fortes enraizamentos e demarcações claras. Pois nossas cidades são hoje o ambíguo, enigmático cenário de algo não representável nem a partir da diferença excludente e excluída do autóctone nem a partir da inclusão uniformizante e dissolvente do moderno.

A heterogeneidade simbólica da cidade, quase impossível de ser alcançada, tem sua expressão mais correta nas mudanças

\section{O AUTOR}

\section{Jesús Martín-Barbero}

Filósofo. Assessor do Instituto de Estudos sobre Culturas e Comunicação da Universidade Nacional, Colômbia.

1. Originalmente publicado em: MARTÍN-BARBERO, Jesús. La ciudad virtual: transformaciones de la sensibilidad y nuevos escenarios de comunicación (A cidade virtual: transformações da sensibilidade e novos cenários de comunicação). Revista de la Universidad de Valle. Cali: Univalle, n. 14, ago. 1996, p.26-38. No Brasil, este artigo foi publicado pela primeira vez pela revista Margem, da Faculdade de Ciências Sociais da PUC-SP, com tradução de Sílvia Borelli. MARGEM. São Paulo: Educ, n.6, novembro de 1997. 
que atravessam não só os modos de experimentar o pertencimento ao território como também as formas de viver a identidade. Mudanças que se encontram, senão determinadas, ao menos fortemente associadas às transformações tecnoperceptivas da comunicação, ao movimento de desterritorialização e internacionalização dos mundos simbólicos e ao descolamento de fronteiras entre tradições e modernidade, entre local e global, entre cultura letrada e cultura audiovisual. $\mathrm{Na}$ investigação sobre esses novos modos de estar juntos aparecem em primeiro plano as transformações da sensibilidade que os acelerados processos de modernização urbana produzem e os cenários de comunicação que, em suas fragmentações e fluxos, conexões e redes, a cidade virtual apresenta.

\section{MODERNIZAÇÃO URBANA \\ E DES-CENTRAMENTO \\ DA EXPERIÊNCIA SOCIAL}

O historiador José Luís Romero foi o primeiro a pensar a modernização das cidades latino-americanas em sua especificidade antropológica: as mudanças nos modos de estar e sentir-se juntos, a desarticulação das formas tradicionais de coesão e a modificação estrutural das formas de socialidade: "Houve uma espécie de explosão da população, e não se podia medir nem em quanto numericamente ela aumentara e nem quanto aumentara a decisão para se conseguir que se contasse com eles e que fossem ouvidos. Eram as cidades que começavam a massificar-se. A rigor, essa massa não tinha um sis- tema coerente de atitudes nem um conjunto harmonioso de normas. Cada grupo tinha as suas. A cidade já não possuía um estilo de vida e sim muitos modos de vida sem um estilo"2.

A massa, marginal durante muito tempo, invadia o centro da cidade e o ressignificava, impondo a ruptura ostensiva das formas de "urbanidade", pois apenas sua presença já implicava um desafio radical à ordem estabelecida das exclusões e dos privilégios, já que o desejo mais secreto dessa massa era ter acesso aos bens que a cidade representava. E ao mesmo tempo a cidade se transformava com o aparecimento do "folclore aluvião", a moderna cultura urbana, a do tango e do futebol, feita de mestiçagem e impurezas, de pateticismo popular e arrivismo burguês. Saída do subúrbio, a cultura popular-de-massa dá forma ao estalido da cidade. Romero vislumbrou certeiramente o que a urbanização das sociedades latino-americanas continha de massificação estrutural e de fragmentação sociocultural.

Na Colômbia, os processos de massificação se revestem, desde o princípio, de duas peculiaridades notórias: antes que à modernização industrial, política ou cultural, eles aparecem ligados à violência ${ }^{3}$ dos fins dos $\operatorname{anos} 40$ a meados dos 60 , que levou milhões de camponeses a abandonar suas terras invadindo as cidades, obrigando-as a reorganizar-se de modo compulsivo, isto é, sem o espaço de tempo e o mínimo de planificação que essa reorganização requereria; a segunda peculiaridade reside no fato de que o êxodo rural não se voltou apenas sobre umas poucas grandes cidades - Bogotá, Cali, Medellin -, como aconteceu com as migrações na maio-

2. ROMERO, José Luís. Latinoamérica: las ciudades y las ideas (América Latina: as cidades e as idéias). México: Siglo XXI, 1976. p.319. Las ideologias de la cultura nacional (As ideologias da cultura nacional). Buenos Aires: CEDAL, 1982.

3. Dois balanços decísivos "da violência" e suas repercussões sobre a vida do país: BEJARANO, J., FALS BORDA et al. Once ensayos sobre la violência (Onze ensaios sobre a violência). Bogotá: Cerec, 1985. PECAUT, D. Orden y violência. Colombia 1930-1953 (Ordem e violência. Colômbia 1930-1953). Bogotá: Siglo XX1, 1987. 
ria da América Latina, e sim afetou também a uma multiplicidade de cidades intermediárias, como Bucaramanga, Pereira ou Neiva, e inclusive cidades que não passavam de 20 mil habitantes ${ }^{4}$. Só a partir de meados dos anos 60 é que a urbanização vai responder a uma modernização industrial e ao início de uma transformação geral das condições de vida e dos costumes tradicionais. Transformação que terá para a Colômbia também um significado especial: instalado em persistente isolamento, em um "ensimesmamento interiorizado"s, o país inicia por esses anos um processo de internacionalização que lhe permite ampliar tanto a visão do mundo como a de si mesmo, questionar o que durante muitos anos se acreditou imodificável e refazer a percepção de sua própria identidade.

Tudo o que se disse até aqui exige que se diferencie a aparição do modernismo arquitetônico, que os historiadores situam em meados dos anos $30^{6}$, dos processos de modernização da vida urbana. Essa diferenciação evidencia uma chocante assimetria, denunciada assim por alguns arquitetos italianos visitantes de Bogotá: "Como podem vocês construir uma cidade tão pobre em termos de qualidade de vida, com tão precário entorno urbano, ao redor de uma arquitetura de tão boa qualidade estética?" 7 . Estamos nos referindo, então, aos processos que es- tão transformando a configuração da cidade: a explosão espacial que apaga suas fronteiras com os municípios ao redor, formando conurbações gigantescas ao redor das grandes cidades, a diversificação de propostas de hábitat - condomínios multifamiliares fechados, enormes edifícios de apartamento, micro-cidades inseridas e às vezes segregadas pela privatização das ruas que lhe dão acesso - desfazendo e refazendo as formas de socialidade, transformando o sentido do bairro ou a função dos espaços públicos; a estandartização dos usos da rua, dos lugares de espetáculos, do comércio, do esporte; a destruição ou ressignificação do centro e de territórios e lugares chaves para a memória cidadã.

Se de um lado urbanização significa acesso aos serviços (água potável, energia, saúde, educação), descomposição das relações patriarcais e certa visibilidade e legitimação das culturas populares, de outro, significa também desenraizamento e crescimento da marginalização, radical separação entre trabalho e vida e perda constante da memória urbana.

Como no resto da América Latina, o processo modernizador da urbanização na Colômbia ${ }^{8}$ responde a três tipos de dinâmica

4. APRILE-GNISET, J. La cuestión urbana hoy: balance, tendências y perspectivas (A questão urbana hoje: balanço, tendências e perspectivas). In: VV.AA. La problemática urbana hoy en Colombia. Bogotá: CINEP, 1982.p.118 e segtes.

5. GILARD, J. Veinte y cuarenta años de algo peor que la soledade (Vinte e quarenta anos de algo pior que a solidão). Bogotá: Nueva Época, 1988.

6. SALDARRIAGA, A. Arquitectura y cultura en Colombia (Arquitetura e cultura na Colômbia). Bogotá: Universidade Nacional, 1986.

7. Citado por VIVIESCAS, F. La dimensión cultural y simbólica de la ciudad (A dimensão cultural e simbólica da cidade). Desde la región (Desde a região). Medellin, n.19, 1995. p.11. E sobre o modernismo arquitetônico na Colômbia, ver: . La arquitectura moderna: los esguinces a la historia (A arquitetura moderna: dos entorses à história) . In:

Colombia: el despertar de la modernidad (Colômbia: o despertar da modernidade). Bogotá: Foro, 1991. Também ver: SALDARRIAGA, A. Arquitectura y cultura en Colombia (Arquitetura e cultura na Colômbia). Bogotá: Universidade Nacional, 1986. El extravio de la belleza (O extravio da beleza). In: de século). Bogotá: EUN, 1994. Arquitectura fin de siglo (Arquitetura fim

8. CELIS, Uribe C. La mentalidad del colombiano: cultura y sociedad en el siglo XX (A mentalidade do colombiano: cultura e sociedade no século XX). Bogotá: Alborada, 1992. MORSE, R., HARDOY, J. E. (comp.). Cultura urbana latinoamericana (Cultura urbana latino-americana). Buenos Aires: Clacso,1985. ORTIZ, R. Mundialização e cultura. São Paulo: Brasiliense, 1994. 
bem diversas mas complementares. Uma, o desejo e a pressão das maiorias para conseguir melhores condições de vida, isto é, as novas aspirações e demandas que emergem a partir de meados dos anos 70 com os novos movimentos sociais, como as manifestações cívicas, a partir dos quais se constroem alternativas de motivação e aglutinação dos setores populares, como os movimentos feministas, que dão forma à autonomia conquistada pelas mulheres, e as organizações não-governamentais, que configuram novos modos de ação política $\mathrm{e}$ de participação cidadã. Dois, a cultura do consumo que nos chega dos países centrais, revolucionando os modelos de comportamento e os estilos de vida, dos costumes alimentares às modas no vestir-se, aos modos de divertir-se, às maneiras de ter acesso aos signos sociais de status. O impulso dessa cultura se acha na modernidade-mundo, que o acelerado e ambíguo processo de globalização da economia e da cultura produz. E três, as novas tecnologias comunicacionais, que pressionam para uma sociedade mais aberta e interconectada, que agilizam os fluxos de informações e as transações internacionais, que revolucionam as condições de produção e de acesso ao saber, mas ao mesmo tempo apagam memórias, transtornam o sentido do tempo e a percepção do espaço, ameaçando as identidades, pois é nelas que se configuram os imaginários em que se plasmam os novos sentidos que, em sua heterogeneidade, hoje cobrem tanto o local quanto os modos de pertencimento e reconhecimento que fazem a identidade nacional.
Dois âmbitos aparecem como especialmente reveladores das mudanças produzidas pelo processo modernizador: o mundo popular e o dos jovens. $\mathrm{O}$ mundo popular se insere na dinâmica urbana através das transformações da vida do trabalho, da identificação das ofertas culturais com os meios massivos, do progresso dos serviços públi$\cos$, da resistência à mudança a partir de sua incerta relação com o estado e sua distância do desenvolvimento tecnológico, da persistência de elementos que vêm da cultura oral, da manutenção das formas populares de transmissão do saber, da refuncionalização do machismo como chave de sobrevivência e dos usos "práticos" da religião.

Retomando a E. P. Thompson", podemos falar da memória de uma "economia moral" que, a partir do mundo popular, atravessa a modernização e se faz visível no sentido da festa que, da celebração familiar do batismo ou da morte ao festival do bairro, integra sabores culturais e saberes de classe, transações com a indústria cultural e afirmações étnicas. Ou essa outra vivência do trabalho, que subjaz à chamada "economia-informal", na qual se revolve o rebus$q u e^{10}$ como estratégia de sobrevivência marginal, incentivada ou consentida pela própria política econômica neoliberal, com o que nos setores populares ainda resta de resistência a uma organização do trabalho incompatível com certa percepção do tempo, certo sentido da liberdade e do valor do familiar. Trata-se de uma economia outra que mostra que nem todo destempo em relação à modernidade é pura anacronia, pode ser também resíduo ${ }^{11}$ não integrado de uma ain-

9. THOMPSON, E. P. Tradición, revuelta y conciencia de classe (Tradição, revolta e consciência de classe). Barcelona: Crítica, 1979.

10. Foi mantida a palavra do texto original, cujo sentido se relaciona a "refugo, rebotalho, o que fica e não presta, resto". (Dicionário espanhol-português, de Júlio Martínez Almoína, Porto Editora) (N.T.)

11. Veja-se a noção de "formação cultural" residual "por oposição às formaçōes arcaica e emergente. WILLIANS, R. Teoría cultural (Teoria cultural). In: Marxismo y Literatura (Marxismo e literatura). Barcelona: Península, 1980. 
da obstinada utopia. Ou o chisme e o chiste, em muitos casos modo de comunicação que veicula contrainformação, os quais, ao mesmo tempo que vulnerável às manipulações da mídia, configuram manifestações das potencialidades da cultura oral sobejamente reconhecidas ${ }^{12}$. Também o centro de nossas cidades é com frequiência um lugar popular de choques e negociações culturais "entre o tempo homogêneo e monótono da modernidade e de outros calendários, os das estações, os das colheitas e os religiosos"13. No centro se podem descobrir os tempos das colheitas das frutas, enquanto os candeeiros, os ramos ou as estampas anunciam a Semana Santa, o mês dos defuntos ou as festas dos santos patronos.

Olhando do outro lado, ou seja, a partir da configuração dos gostos e dos imaginários populares, as telenovelas colombianas ${ }^{14}$ - de Gallito Ramírez até Café passando por Cavalo Velho por séries como História de Tita, A casa das duas palmas, Maria Maria ou Sonhos e Espelhos - desenharam um mapa bem diferente daquele ao qual a retórica desenvolvimentista nos tem acostumado: um mapa expressivo das descontinuidades e dos destempos, como também das secretas vizinhanças e intercâmbios entre modernidade e tradições, entre o país urbano e o país rural. É um mapa com populações a meio caminho entre o povoado camponês e o bairro da cidade, com povoados onde as relações sociais já não têm a estabilidade nem a transparência - a elementaridade - do rural, e com bairros que são o âmbito no qual sobrevivem, inter-relacionadas, relações verticais e autoritarismos feudais com a horizontalida- de tecida no rebuscamento e na informalidade urbanas. Os povoados mostram seu definhamento demográfico e a centralidade que ainda ocupa a religião, mas ao mesmo tempo aparecem as transformações que a energia elétrica, o telefone, o cinema, o trator, a motocicleta, o rádio, a água corrente, a televisão, o biorritmo introduzem: mudanças que não afetam só o âmbito do trabalho ou da casa, mas também a afetividade, a subjetividade, a sensualidade. Por sua parte o subúrbio - nossos extensos bairros de invasão, como Aguablanca em Cali, as comunidades noroorientais em Medellin ou Cidade Bolívar em Bogotá - aparecem como lugar estratégico de reciclagem cultural: entre a cumplicidade que permite tirar partido dos vícios dos ricos, e a resistência que guarda resíduos de solidariedades e generosidades a toda prova, vemos formar-se uma trama de intercâmbios e exclusões que, ainda que esquematicamente, fala do cruzamento entre a violência que se sofre e aquela outra com a qual se resiste, e das transações morais sem as quais resulta impossível sobreviver na cidade.

$\mathrm{Na}$ trama que esses intercâmbios tecem, se faz vísivel a impossibilidade de continuar pensando separadamente os processos da modernização industrial e tecnológica das dinâmicas culturais da modernidade. Questionando corretamente esse dualismo, F. Giraldo e H. F. López colocam: "O marginalizado que habita nos grandes centros urbanos da Colômbia e que, em algumas cidades, assumiu a figura do sicário, não é apenas a expressão do atraso, da pobreza ou do desemprego; a ausência da ação do Estado em seu lugar de moradia e de

12. RIAÑO, P. Prácticas culturales y culturas populares (Práticas culturais e culturas populares). Bogotá: CINEP, 1986. E sobre outras estratégias e gêneros da cultura oral: VILLA MEJíA, V. Polisin-fonías (Polissinfonias) (segunda parte). Medellin: Caribe, 1993.

13. ECHEVARRIA CARVAJAL. Itinerarios y metáforas: agorazein (Intinerários e metáforas: agorazein). Medellin: Universidad Nacional, Tesis, 1995, p.34.

14. MARTÍN-BARBERO, J. De la telenovela en Colombia a la telenovela colombiana (Da telenovela na Colômbia à telenovela colombiana). In: Televisión y melodrama (Televisão e melodrama). Bogotá: Tercer Mundo, 1992. 
uma cultura que finca suas raízes na religião católica e na violência política. Também é o reflexo, por acaso de maneira mais evidente, do hedonismo e do consumo, da cultura da imagem, do vício da droga, em uma palavra, da colonização do mundo da vida pela modernidade" 15 .

A compreensão de nossa modernidade periférica está exigindo pensar juntos a inovação e a resistência, as continuidades e as rupturas, o descompasso no ritmo das diferentes dimensões da mudança e as contradições não só entre diferentes âmbitos - tecnológico, político, social - mas também entre diversos planos de um mesmo âmbito.

Falar nesses países de pseudomodernidade, ou opor modernidade a modernização, resulta algumas vezes sugestivo e pedagogicamente cômodo, mas acaba legitimando a visão destes povos como meros reprodutores $e$ deformadores da verdadeira modernidade que os países do centro construíram. Desse modo, somos impedidos de compreender a especificidade dos processos, a peculiaridade dos ritmos e a densidade de mestiçagens e destempos em que se produz a nossa modernidade. Por isso não é estranho que, diante dos tapumes que as demarcações traçadas pelas disciplinas erigem, de seus prestígios acadêmicos e de suas inércias políticas, sejam intelectuais ou artistas não restritos a essas demarcações os que melhor percebam e expressem as hibridizações do mundo popular urbano: "Em nossos bairros populares temos camadas inteiras de jovens, e até de adultos, cujas cabeças aceitam a magia e a feitiçaria, as culpas cristãs e a sua intolerância piedosa, do mesmo modo que o messianismo e o dogma estreito e retesado, até utópicos sonhos de igualdade e liberdade, indiscutíveis e legítimos, e também sensações de vazio, ausência de ideologias totalizadoras, fragmentação da vida e tirania da imagem fugaz, com o som musical como única linguagem de fundo" 16 .

No que concerne ao mundo dos jovens, as transformações apontam para a emergência de sensibilidades "desligadas das figuras, estilos e práticas de velhas tradições que definem 'a cultura' e cujos sujeitos se constituem a partir da conexão/desconexão com os aparelhos"17. Isso se evidencia em uma "plasticidade neuronal" que os dota de uma grande facilidade para os idiomas da tecnologia. Essa empatia dos jovens com a cultura tecnológica vai da informação absorvida pelo adolescente em sua relação com a televisão - que corrói seriamente a autoridade da escola como única instância legítima de transmissão de saberes - à facilidade para entrar na complexidade das redes informáticas e manejá-las.

Frente à distância e prevenção com que grande parte dos adultos ressentem e resistem a essa nova cultura - que desvaloriza e coloca como obsoletos muitos de seus saberes e destrezas, e à qual, de sua parte, responsabilizam pela decadência dos valores intelectuais e morais de que padece hoje a sociedade - os jovens experimentam uma empatia feita não só de facilidade para relacionar-se com as tecnologias audiovisuais e informáticas, mas também de cumplicidade expressiva: é em seus relatos e imagens, em suas sonoridades, fragmenta-

15. GIRALDO, F., LÓPEZ. H. F. La metamorfosis de la modernidad (A metamorfose da modernidade). In: Colombia: el despertar de la modernidad (Colombia: o despertar da modernidade). Bogotá: Foro, 1991. p.391.

16. CRUZ KRONFLY, F, El intelectual en la nueva Babel colombiana (O intelectual na nova Babel colombiana). In: Colombia: el despertar... idem. ibid. p.391.

17. RAMIREZ, S., MUÑOZ, S. Trayetos del consumo (Trajetos do consumo). In: de investigação). Cali: Univalle, 1995. p. 60. Informe de investigación (Informe 
ções e velocidades que eles encontram seu idioma e seu ritmo. Pois, frente às culturas letradas, ligadas à língua e ao território, as eletrônicas, audiovisuais, musicais, ultrapassam essa limitação, produzindo comunidades hermenêuticas que respondem a novos modos de perceber e narrar a identidade. Identidades de temporalidades menos extensas, mais precárias, mas também mais flexíveis, capazes de amalgamar e fazer conviver ingredientes de universos culturais muito diversos.

Sua melhor expressão talvez seja o rock em espanhol: idioma no qual se manifesta a mais profunda brecha geracional e algumas das transformações mais de fundo que a cultura política está sofrendo. Ligado inicialmente a um sentimento pacifista grupos Gênesis e Banda Nova - esse rock se associa nos últimos anos à experiência urbana dos bandos juvenis nos bairros de classe média baixa em Medellin e classe média alta em Bogotá, convertendo-se em veículo de uma consciência dura da descomposição do país, da presença cotidiana da morte nas ruas, da situação sem saída para o trabalho, da falta de ação moral e da exasperação da agressividade e do macabro.

Desde a estridência sonora do Heavy Metal aos nomes dos grupos - Féretro, $A$ pestilência, Kraken - passando pelas estratégias que o mercado do disco, do rádio ou da aparelhagem tecnológica dos concertos the impõe, esse rock torna audíveis sonoridades que vêm das culturas regionais e sensibilidades que recolhem os ruídos e os sons de nossas cidades, a solidão hostil e o desenraizamento.
Além do que revelam esses dois âmbitos, a modernização urbana se identifica cada dia mais estreitamente - tanto na racionalidade hegemônica que inspira a planificação dos urbanistas quanto na contraditória experiência dos cidadãos ou na resistência que os movimentos sociais opõem - com o paradigma de comunicação a partir do qual está sendo regulado o caos urbano.

Trata-se do paradigma informacional ${ }^{18}$, centrado no conceito de fluxo, entendido com tráfico ininterrupto, interconexão transparente e circulação constante de veículos, pessoas e informações. A verdadeira preocupação dos urbanistas não será, portanto, que os cidadãos se encontrem e sim que circulem, porque já não se quer os cidadãos reunidos e sim conectados. Por isso é que não se constroem praças nem se permitem cantinhos, e o que aí se perde pouco importa, pois na "sociedade da infomação" o que interessa é a ganância na velocidade de circulação.

De que maneira o cidadão experimenta a ambígua modernização que, sob o paradigma do fluxo, vivem nossas cidades e suas formas de habitá-la, de padecer nelas e resistir. Esquematicamente descobriremos três: a des-espacialização, o des-centramento e a des-urbanização.

Des-espacialização significa, em primeiro lugar, que o espaço urbano não conta senão enquanto valor associado ao preço do solo e ao modo que ele se inscreve nos movimentos do fluxo veicular: "é a transformação dos lugares em espaços de fluxos e canais, o que equivale a uma produção e um consumo sem localização alguma"19. A materialidade histórica da cidade em seu

18. Os textos inaugurais desse paradigma: SHANON, C. E., WEAVER, W. Teoría matemática de la comunicación (Teoria matemática da comunicação). Madrid: Forja, 1981. WIENER, N. Cibernética y sociedad (Cibernética e sociedade). Buenos Aires: Sudamericana, 1969.

19. CASTELLS, M. La ciudad y las masas (A cidade e as massas). Madrid: Alianza, 1983. __. El nuevo entorno tecnológico de la vida cotidiana (O novo entorno tecnológico da vida cotidiana). In: nológico). Madrid: Alianza, 1986. 
conjunto sofre assim uma forte desvalorização, seu "corpo-espaço" perde peso em função do novo valor que o seu tempo, "o regime geral da velocidade" 20 , adquirem. Não é difícil ver aqui a conexão que une essa descorporização da cidade ao fluxo, cada dia mais denso, das imagens, desvalorizando e até substituindo o intercâmbio de experiências entre as pessoas. Assumindo essa realidade como uma mutação cultural de longo alcance, G. Vattimo a associa ao "debilitamento do real"2ı que o desenraizado homem urbano experimenta na fabulação que a constante mediação e entrecruzamento de informações e de imagens produz. Mas o desenraizamento urbano remete à outra cara da des-espacialização, colocada abaixo desse bosque de imagens, ao apagamento da memória que uma urbanização racionalizadamente selvagem produz. O fluxo tecnológico convertido em álibi de outros fluxos mais interessados desvaloriza a memória cultural até justificar seu arrasamento. E sem referentes aos quais poderia agarrar seu reconhecimento, os cidadãos sentem uma insegurança muito mais profunda que aquela que vem da agressão direta dos delinqüentes, uma insegurança que é angústia cultural e pauperização psíquica, a fonte mais secreta e certa da agressividade de todos.

Com des-centramento da cidade queremos assinalar não a tão falada descentralização mas a "perda de centro". Pois não se trata só da degradação sofrida pelos centros históricos e sua recuperação "para turistas" (ou boêmios, intelectuais etc.) e sim da proposta de uma cidade configurada a partir de circuitos conectados em redes cuja topologia supõe a equivalência de todos os lugares. E, desse modo, a supressão ou desvalorização daqueles lugares que faziam função de centro, como as praças. $O$ descentramento que estamos descrevendo aponta justamente para um ordenamento que privilegia as avenidas retas e diagonais, em sua capacidade de operacionalizar entrelaçamentos, conexões de fluxos versus intensidade do encontro e a periculosidade da aglomeração que a praça possibilitava. A única centralidade que a cidade admite hoje é subterrânea, no sentido que lhe dá M. Maffesoli22, e que remete sem dúvida à multiplicação dos dispositivos de entrelaçamento do poder tematizada por Foucault ${ }^{23}$.

Restam-nos, agora no plural e em sentido "desfigurado", os centros comerciais, que reordenam o sentido do encontro entre as pessoas, isto é, funcionam como espetáculo arquitetônico e cenográfico do comércio e con-centram as atividades que a cidade moderna separou: $o$ trabalho e o ócio, o mercado e a diversão, as modas elitistas e as magias populares.

Des-urbanização indica a redução progressiva da cidade que é realmente usada pelos cidadãos. $\mathrm{O}$ tamanho e a fragmentação conduzem ao desuso por parte da maioria não só do centro mas também de espaços públicos carregados de significação durante mui-

20. VIRÍLIO, P. La máquina de visión (A máquina de visão). Madrid: Cátedra, 1989. (Estética da desaparição). Barcelona: Anagrama, 1988. El último vehiculo $(\mathrm{O}$

Estética de la desaparición turas fin de siglo (Videoculturas do fim do século). Madrid: Cátedra, 1989 dão). Cuadernos del Norte (Cadernos do Norte). Oviedo: [s.n.], n.57, 1990.

21. VATTIMO, G. La sociedad transparente (A sociedade transparente). Barcelona: Paidós, 1990.

22. MAFFESOLI, M. La hipótesis de la centralidad subterránea (A hipótese da centralidade subterrânea). Dia-logos de la comunicación. Lima, FELAFACS, n.23, 1989. Identidad y identificación en las sociedades contemporáneas (Identidade e identificação nas sociedades contemporâneas). In: Pablo Iglesias, 1990.

23. FOUCAULT, M. Un diálogo sobre el poder (Um diálogo sobre o poder). Madrid: Alianza, 1981. 
to tempo. A cidade vivida e gozada pelos cidadãos se estreita, perde seus usos ${ }^{24}$. As pessoas também traçam seus circuitos, que apenas atravessam a cidade quando obrigados pelas rotas de tráfico, andando ao seu redor quando podem, em um uso puramente funcional. Haveria também outro sentido para o processo de desurbanização: o da $r u$ ralização de nossas cidades. Tal qual a urbanização física, a cultura da maioria que as habita se acha a meio caminho entre a cultura rural em que nasceram - eles, seus pais ou ao menos seus avós - já corroída pelas exigências que a cidade impõe, e os modos de vida plenamente urbanos. $\mathrm{O}$ aumento brutal da pressão migratória nos últimos anos e a incapacidade de os governos municipais para frear pelo menos a deterioração das condições de vida da maioria estão fazendo emergir a "cultura do rebusque", que faz vigir de novo "velhas" formas de sobrevivência rural, que inserem, nas aprendizagens e apropriações da modernidade urbana, saberes e relatos, sentimentos e temporalidades fortemente rurais ${ }^{25}$.

Podemos continuar falando, então, de Medellin, de Bogotá ou de Cali como de uma cidade? Excluindo a folclorizada retórica dos políticos e a nostalgia dos jornalistas "locais", que nos recordam cotidianamente os costumes e os lugares "próprios", o que compartilham verdadeiramente as pessoas dos bairros semi-rurais de Aguablanca, com as de Santa Teresinha ou São Fernando, com as das novas classes médias de Tequendama e com os velhos e novos ri- cos de Cidade Jardim em Cali? Serão o clube de futebol América e a música salsa? Na cidade fraturada e descentrada, o que poderia motivar hoje as pessoas a juntarem-se, que imaginários aglutinantes fazem e em que se apóiam os reconhecimentos?26. É óbvio que os diversos setores sociais não sentem a cidade a partir das mesmas referências materiais e simbólicas. Mas estamos nos referindo a outro plano: à heterogeneidade de referentes identificatórios que propõe, à precariedade dos modos de enraizamento ou de pertencimento, à expansão estrutural do anonimato e às novas formas de comunicação que a própria cidade agora produz.

\section{MEIOS, FLUXOS E REDES: OS NOVOS CENÁRIOS DE COMUNICAÇÃO}

A hegemonia do paradigma informacional sobre a dinâmica do urbano leva a descobrir que a cidade já não é só um "espaço ocupado" ou construído, mas é também um espaço comunicacional, que conecta entre si seus diversos territórios e os conecta com o mundo. Há uma estreita simetria entre a expansão/fratura da cidade e o crescimento/adensamento dos meios e as redes eletrônicas. Se as novas condições de vida na cidade exigem a reinvenção de laços sociais e culturais "são as redes audiovisuais as que efetuam, a partir de sua própria lógica, uma nova diagramação dos espaços e intercâm-

24. CANCLINI, N. García, PICCINI, M. Culturas de la ciudad de México: símbolos colectivos y usos del espacio urbano (Culturas da Cidade do México: símbolos coletivos e usos do espaço urbano). In: El consumo cultural en México (O consumo cultural no México), México: CONACULTA, 1993, p.49.

25. A esse propósito ver: MONSIVAIS, C. La cultura popular en el ámbito urbano (A cultura popular no âmbito urbano). In: Comunicación y culturas populares en latinoamérica (Comunicaçāo e culturas populares na América Latina). México: Felafacs/G. Gilli, 1987. Também na obra: ARAMUS (org.). Mundo urbano y cultura popular (Mundo urbano e cultura popular). Buenos Aires: Sudamericana, 1990.

26. Uma tentativa pioneira, na Colômbia, para entender essas questōes é a investigação de: SILVA, A. Imaginarios urbanos. Bogotá: Tercer Mundo, 1992. 
bios urbanos"27. Na cidade disseminada e impossível de ser inteiramente abarcada, só os meios de comunicação possibilitam uma experiência-simulacro da cidade global. É na televisão, onde a câmera do helicóptero nos permite ter acesso a uma imagem da densidade do tráfego nas avenidas ou da vastidão e desolação dos bairros de invasão. É na TV ou na rádio que cotidianamente conectamos com o que acontece na cidade "que vivemos" e nos envolvemos com os acontecimentos, por mais longe que deles estejamos: do massacre do palácio da justiça ao contágio de AIDS no banco de sangue de uma clínica, do acidente de tráfego que bloqueia a avenida pela qual devo chegar ao meu trabalho, aos avatares da política que fazem cair os valores na bolsa. Na cidade dos fluxos comunicativos contam mais os processos que as coisas, a ubiqüidade $\mathrm{e}$ instantaneidade da informação ou da decisão via telefone celular ou fax, incluindo desde o computador pessoal até à facilidade e rapidez dos pagamentos ou aquisição de dinheiro por cartões. A imbricação entre televisão e informática produz uma aliança entre velocidades audiovisuais e informacionais, entre inovações tecnológicas e hábitos de consumo: "Um ar de família vincula a variedade das telas que reúnem nossas experiências de trabalho, domésticos e lúdicas" 28 , atravessando e reconfigurando as experiências da rua e até as relações com nosso corpo, um corpo sustentado cada vez menos em sua anatomia e mais em suas extensões ou próteses tecnomediáticas: a cidade informatizada não necessita corpos reunidos e sim interconectados.
Pois bem, o que constitui a força e a eficácia da cidade virtual, que os fluxos informáticos e as imagens televisivas entretecem, não é o poder das tecnologias em si mesmas e sim sua capacidade de acelerar de amplificar e aprofundar - tendências estruturais de nossa sociedade. Como afirma F. Colombo, "há um evidente desnível de vitalidade entre o território real e o proposto pelos meios de comunicação. A possibilidade de desequilíbrios não deriva do excesso de vitalidade dos meios, antes disso provém da debilitada, confusa e exaurida relação entre os cidadãos do território real"29. O desequilíbrio urbano gerado por um tipo de urbanização irracional é, de alguma forma, compensado pela eficácia comunicacional das redes eletrônicas.

Pois em cidades cada dia mais extensas e desarticuladas, nas quais as instituições políticas "progressivamente separadas do tecido social de referência se reduzem a ser sujeitos do evento espetacular, em igualdade com outros" 30 , o rádio e a televisão acabam sendo o dispositivo de comunicação capaz de oferecer formas de opor-se ao isolamento das populações marginalizadas, estabelecendo vínculos culturais comuns à maioria da população.

Na Colômbia, isso se viu reforçado nos últimos anos por uma especial cumplicidade entre meios e medos. Tanto a atração quanto a incidência da televisão sobre a vida cotidiana tem menos que ver com sua programação do que com o que leva as pessoas a

27. CANCLINI, N. Garcia. Culturas de la Ciudat de México: símbolos colectivos y usos del espacio urbano (Culturas da Cidade do México: símbolos coletivos e usos do espaço urbano) p.49 y também: Del espacio político a la teleparticipa. ción (Do espaço político à teleparticipação). In: Culturas híbridas. México: Grijalbo, 1990.

28. FERRER, C. Taenia saginata o el veneno en la red (Taenia saginata ou o veneno na rede). Nueva Sociedad (Nova Sociedade). Caracas: [s.n.]. n. 140, 1995. p. 155.

29. COLOMBO, F. Rabia y televisión (Raiva e televisão). Barcelona: Gustavo Gili, 1983. p.47.

30. RICHERI, G. Crisis de la sociedad y crisis de la televisión (Crises da sociedade e crises da televisão). Contratexto. Lima: [s.n.], n.4. 1989. 
resguardar-se no espaço doméstico. Como escrevi em outra parte, em boa medida "se a televisão atrai é porque a rua expulsa, é dos medos que vivem os meios" 31 . Medos que provêm secretamente da perda do sentido de pertencimento em cidades nas quais a racionalidade formal e comercial vem acabando com a paisagem em que se apoiava a memória coletiva. São cidades que, ao normalizar tanto as condutas quanto os edifícios, corroem as identidades e essa erosão acaba roubando-nos o piso cultural, lançando-nos no vazio. Medos, enfim, que provêm de uma ordem construída sobre a incerteza e a desconfiança que o outro nos produz, qualquer outro - étnico, social, sexual - que se aproxima de nós na rua e é compulsivamente percebido como ameaça.

Ao crescimento da insegurança, a cidade virtual responde expandindo o anonimato que possibilita o não-lugar ${ }^{32}$ : esse espaço no qual os indivíduos são liberados de toda a carga de identidade interpeladora e exigidos unicamente na sua interação com informações ou textos. É o que vive o comprador no supermercado ou o passageiro no aeroporto, onde o texto informativo ou publicitário vai guiando-o de uma ponta à outra sem necessidade de trocar uma palavra durante horas.

Comparando as práticas de comunicação nos supermercados com as das praças populares de mercado, constatamos que já faz vinte anos que houve a substituição da interação comunicativa pela textualidade informativa: "Vender ou comprar na praça de mercado é enredar-se em uma relação que exige falar. Aí, enquanto o homem vende, a mulher ao seu lado amamenta o filho, e se o comprador deixar, lhe contará o quanto foi ruim o último parto. É uma comunicação que parte da expressividade do espaço junto ao calendário de mulher pelada, uma imagem da Virgem do Carmo está colocada lado a lado com a do campeão de boxe e uma cruz de madeira pintada em purpurina sustenta um maço de sávia -, através da qual o vendedor nos fala de sua vida, e chega-se até ao regateio, que é possibilidade e exigência de diálogo. Em contraste, você pode fazer todas as suas compras no supermercado sem falar com ninguém, sem ser interpelado por ninguém, sem sair do narcisismo especular que o leva de uns objetos a outros, de umas "marcas" a outras. No supermercado só há informação que os avisos ou a publicidade transmitem" 33 . E o mesmo ocorre nas autopistas. Enquanto as "velhas" estradas atravessavam as populações convertendo-se em ruas, contagiando o viajante do "ar do lugar", de suas cores e ritmos, a autopista, volteando os centros urbanos, só chega a eles através dos textos das placas que "falam" dos produtos do lugar e de seus pontos interessantes.

Não pode, então, parecer estranho que as novas formas de habitar a cidade do anonimato, especialmente pelas gerações

31. MARTÍN-BARBERO, J. La ciudad: entre medios y miedos (A cidade: entre meios e medos). In: xiones de la cultura em Colombia (Imagens e reflexões da cultura na Colômbia). Bogotá: Colcultura, 1990.

32. AUGÉ, M. Los no-lugares. Espacios del anonimato (Os não-lugares. Espaços do anonimato). Barcelona: Gedisa, 1993. Em uma perspectiva convergente: JOSEPH, Y. El transeúnte y el espacio urbano ( $\mathrm{O}$ transeunte e o espaço urbano). Barcelona: Gedisa, 1988. VENTOS, X. Rubert de. El desorden espacial (A desordem espacial). In: el desordem (Ensaios sobre a desordem). Barcelona: Kairos, 1976.

33. MARTÍN-BARBERO, J. Prácticas de comunicación en la cultura popular (Práticas de comunicação na cultura popular). In: SIMPSON, M. (coord.). Comunicación alternativa y cambio social en América Latina (Comunicação alternativa e mudança social na América Latina). México: UNAM, 1981. p.244. La revoltura de pueblo y masa en lo urbano $(\mathrm{A}$ revolta do povo e massa no urbano). In: De los medios a las mediaciones. Barcelona: G. Gilli, 1985. (Dos meios às mediações: hegemonia, comunicação e cultura. Rio de Janeiro: UFRJ, 1997). 
que nasceram com essas cidades, seja inserindo na homogeneização inevitável (do vestido, da comida, da moradia) uma pulsão profunda de diferenciação que se expressa nas tribos $^{34}$ : essas grupalidades novas cujas ligações não provêm nem de um território fixo nem de um consenso racional e duradouro, e sim da idade e do gênero, dos repertórios estéticos e dos gostos sexuais, dos estilos de vida e das exclusões sociais. Parceiros, plásticos, traquetos, guabalosos ou desejáveis são algumas denominações que assinalam a emergência de diferentes grupalidades em Cali 35 ; plásticos, boletas, gomelos, ñeros, nerds, alternativos são as denominações das grupalidades mais freqüentes em Bogotá ${ }^{36}$. Baseadas em implicações emocionais e localizações nômades, essas tribos se entrelaçam em redes ecológicas ou orientalistas que amalgamam referentes locais a símbolos indumentários ou lingüísticos desterritorializados, em uma redefinição das fronteiras do nacional não a partir de fora, sob a figura da invasão, e sim de dentro: na lenta erosão que mostra a arbitrária artificiosidade de demarcações que foram perdendo capacidade de fazer-nos sentir juntos. É o que descobrem para nós, ao longo da América Latina, as investigações sobre as tribos da noite em Buenos Aires, sobre os bandos de garotos em Guadalajara, ou sobre as bandas juvenis das comunidades noroorientais de Medellin ${ }^{37}$. Enfrentando a massificada disseminação de seus anonimatos, e fortemente conectada às redes da cultura-mundo do audiovisual, a heterogeneidade das tribos urbanas nos desvenda a radicalidade das transformações que atravessam o nós, a profunda reconfiguração da socialidade.

Essa reconfiguração encontra seu mais decisivo cenário na formação de um novo sensorium: frente à dispersão e à imagem múltipla que, segundo W. Benjamin, conectavam "as modificações do aparelho perceptivo do transeunte no tráfego da grande cidade" 38 , do tempo de Baudelaire, com a experiência do espectador de cinema, os dispositivos que agora conectam a estrutura comunicativa da televisão com as chaves que ordenam a nova cidade são outros: $a$ fragmentação e o fluxo.

Enquanto o cinema catalisava a "experiência da multidão", pois era em multidão que os cidadãos exerciam seu direito à cidade, o que agora a televisão catalisa é, pelo contrário, a "experiência doméstica" e domesticada, pois é "a partir da casa" que as pessoas exercem agora, cotidianamente, sua participação na cidade.

Falamos de fragmentação para nos referirmos não à forma do relato televisivo e sim à des-agregação social, à atomização que a privatização da experiência televisiva consagra. Constituída em centro das rotinas

34. MAFFESOLI, M. El tiempo de las tribus: el declive del individualismo en la sociedad de masas (O tempo das tribos: o declive do individualismo na sociedade de massa). Barcelona: Icaria, 1990.

35. ULLOA, A. Culturas juveniles, consumo musical y identidades sociales en Cali (Culturas juvenis, consumo musical e identidades sociais em Cali). [s.I: s.n., s.d.]. p.16.

36. MUÑOZ, G. (coord.). El rock en las culturas juveniles urbanas (O rock nas culturas juvenis urbanas). [s.l: s.n., s.d.]. p.89.

37. MARGULIS, M. et al. La cultura de la noche. Vida nocturna de los jóvenes en Buenos Aires (A cultura da noite. Vida noturna dos jovens em Buenos Aires). [s.I.]: Espasa Hoy, 1994. REGUILLO, R. En la calle otra vez. Las Bandas: identidad urbana y usos de la comunicación ( $\mathrm{Na}$ rua outra vez. As bandas: identidade urbana e usos da comunicação). México/Guadalajara: Iteso, 1991. SALAZAR, A. No nacimos pa'semilla. La cultura de las bandas juveniles de Medellin (Não nascemos para semente. A cultura das bandas de jovens de Medellin). Bogotá: Cinep, 1990.

38. BENJAMIN, W. Discursos interrumpidos (Discursos interrompidos). Madrid: Taurus, v.1, 1982. p.47. 
que ritmam o cotidiano ${ }^{39}$, em dispositivo de garantia da identidade individual ${ }^{40} \mathrm{e}$ em terminal de vídeo texto, vídeo-compra, correio eletrônico e teleconferência ${ }^{41}$, a televisão converte o espaço doméstico em território virtual: aquele ao qual, como afirma Virílio, "tudo chega sem que tenha que partir". O que resulta importante compreender, então, não é apenas o encerrar-se, o inclinar-se para a doméstica privacidade, e sim a reconfiguração das relações de privado e do público que aí se produz, isto é, a superposição entre ambos os espaços e o apagamento de suas fronteiras.

O público gira hoje em torno do privado não apenas no plano econômico, mas também no político e cultural. E, reciprocamente, estar em casa já não significa ausentar-se do mundo: "a televisão é hoje em dia a representação mais aproximada do demiurgo platônico; e a fascinação que exerce sobre os seres humanos não tem que ver unicamente com a informação ou com o entretenimento: a oferta televisiva principal é o mundo, o telespectador é um cosmopolita" 42 . O que promove a identificação da cena pública com aquilo que "passa" na televisão não são unicamente as inseguranças e violências da rua. Os meios massivos, e de modo decisivo a televisão, são hoje o equivalente do antigo ágora: o cenário, por antonomásia, da coisa pública.

Cada dia de forma mais explícita a política, tanto a que se faz no Congresso quanto nos ministérios, nos comícios e nos protesto de rua e até nos atentados terroristas, faz-se para as câmeras, que são a nova expressão da existência social. E também o mercado invadiu o âmbito privado convertendo o consumo produtivo em uma força econômica de primeira magnitude: ser telespectador "equivale a converter-se em elemento de uma população analisável estatisticamente em função de seus gostos e preferências que se revelam no consumo produtivo anterior à compra da mercadoria física" 43 .

Ao consumir seu tempo de ócio, a telefamília gera um novo mercado, uma nova mercadoria: o valor do tempo, que é medido pelo nível de audiência dos produtos televisivos. E ainda mais decisivo é o que acontece no plano cultural: enquanto ostensivamente se reduz à presença nos eventos culturais em lugares públicos, tanto da alta cultura (teatros, museus, balé, concertos de música culta) quanto da cultura local popular (atividades de bairro, festivais, feiras artesanais), a cultura a domicílio ${ }^{44}$ cresce e se mul-

39. SILVERSTONE, R. De la sociología de la television a la sociología de la pantalla (Da sociologia da televisão à sociologia da tela). Telos. Madrid, n.22, 1990. MIER, R., PICCINI, M. El desierto de los espejos: juventud y televisión em México (O deserto dos espelhos: juventude e televisão no México). México: Plaza y Valdés, 1987.

40. VEZZETTI. H. El sujeto psicológico en el universo massmediático (O sujeito psicológico no universo massmediático). Punto de Vista. Buenos Aires: n.47, 1993. NOVAES, A. Rede imaginária: televisão e democracia. São Paulo: Cia. das Letras, 1991 .

41. GUBERN, R. El simio informatizado (O simio informatizado). Madrid: Fundesco, 1987. PISCITELLI, A. De las imágenes numéricas a las realidades virtuales (Das imagens numéricas às realidades virtuais). David y Goliath. Buenos Aires: n.57, 1990, Hay vida después de la televisión? (Há vida após a televisão?). Nueva Sociedad. Caracas: n.140, 1995.

42. ECHEVERRÍA, J. Cosmopolítas domésticos (Cosmopolitas domésticos). Barcelona: Anagrama, 1995, p.81.

43. ECHEVERRIA, J. Telépolis. Barcelona: Destino, 1994, p.72.

44. CATALÁN, C., SUNKEL, G. Algunas tendencias en el consumo de bienes culturales en América Latina (Algumas tendências no consumo de bens culturais na América Latina). Santiago do Chile: Flacso, 1992. CANCLINI, N. García (coord.). El consumo cultural en México (O consumo cultural no México). México: Conaculta, 1993. MUÑOZ, S. El ojo, el libro y la pantalla: consumo cultural en Cali (O olho, o livro e a tela: consumo cultural em Cali). Cali: Univalle, 1995. 
tiplica a partir da televisão herziana (que mais de $90 \%$ em média, em toda a América Latina, vê) icluindo a TV a cabo e as antenas parabólicas - que fizeram crescer de forma impensável o número de canais e a quantidade de horas de emissão ${ }^{45}$-, além da videogravadora, que em vários países latino-americanos já supera $50 \%$ de lares. Ao mesmo tempo se "populariza" o uso do computador pessoal, o multimídia e a Internet.

Do povo que toma a rua, ao público que vai ao teatro ou ao cinema, a transição é transitiva e conserva o caráter coletivo da experiência. Dos públicos de cinema às audiências de televisão, o deslocamento assinala uma profunda transformação: a pluralidade social submetida à lógica da desagregação faz da diferença uma mera estratégia de cálculo, de rating. E não sendo representada na política, é o mercado que toma a seu cargo a fragmentação da cidadania: é dessa mudança que a televisão é a principal mediação!

O fluxo televisivo é o dispositivo complementar da fragmentação: não somente da descontinuidade espacial da cena doméstica como também da pulverização do tempo que produz a aceleração do presente, a contração do atual, a "progressiva negação do intervalo", transformando o tempo extensivo da história no intensivo do instantâneo. Isso afeta não somente o discurso da informação (cada dia temporal e expressivamente mais próximo ao da publicidade), mas também ao continuum do palimpsesto televisivo ${ }^{46}$ - a diversidade dos pro- gramas conta menos que a presença permanente da tela acesa - e a forma de representação: o que segura o telespectador é mais o ininterrupto fluxo das imagens que o conteúdo de seu discurso. Há uma conexão de fluxos entre o regime econômico de temporalidade que torna rapidamente obsoletos os objetos e aquele que torna indiferenciáveis, equivalentes e desejáveis os relatos e os discursos da televisão. E não terá algo que ver esse novo regime temporal dos objetos $\mathrm{e}$ os relatos mais acessíveis às maiorias com o crescimento do desassossego e a anomia que, na cidade do fluxo, as pessoas experimentam?

O fluxo televisivo estava exigindo o zapping ${ }^{47}$, esse controle remoto mediante o qual cada um pode, como um nômade, armar sua própria programação com fragmentos ou "restos" de noticiários, telenovelas, concursos ou concertos.

Mas, além da aparente democratização que a tecnologia introduz, a metáfora do zappar ilumina duplamente a cena social. Pois é com pedaços, restos e desejos que boa parte da população arma os barracos em que habita, tece o rebusque com que sobrevive e mescla os saberes com que enfrenta a opacidade urbana.

E há também uma certa e eficaz travessia que liga os modos nômades de habitar a cidade - do emigrante àquele que é obrigado a seguir indefinidamente emigrando dentro da própria cidade, à medida que se vão urbanizando as invasões e valorizando-se os terrenos, até à banda juvenil que periodica-

45. Sobre esse crescimento veja: ALFONZO, A. Televisión de servicio público y televisión lucrativa en América Latina (Televisão de serviço público e televisão lucrativa na América Latina). Caracas: Ministério de la Cultura, 1990.

46. BARLOZZETTI, G. (ed.). II Palinsesto: testo, apparati y generi della televisione. Milano: Franco Angeli. 1986. (O palimpsesto: texto, aparelho e gênero da televisão)

47. Sobre como a lógica do zapping já estava inscrita no fluxo de montagem indiferenciadora das imagens televisivas: SARLO, B. Zapping. In: Escenas de la vida postmoderna (Cenas da vida pós-moderna). Buenos Aires: Ariel, 1993, p.57. 
mente desloca seus lugares de encontro com os modos de ver a partir dos quais o telespectador explora e atravessa o palimpsesto ${ }^{48}$ dos gêneros e os discursos, e com a transversalidade tecnológica que hoje permite enlaçar o terminal informático, o trabalho e o ócio, a informação e a compra, a investigação e o jogo.

Resumo: $\mathrm{O}$ artigo trata das novas formas de socialidade nas grandes cidades, principalmente nas latino-americanas. O fluxo continuo dos veículos, a fragmentação cultural, as "tribos" de jovens, o espaço público esvaziado pelo medo e pela reclusão em frente à televisão, o computador e as facilidades de trânsito alcançados através das novas tecnologias tornam a cidade cada vez menos território de encontro, transformando-a em mera possibilidade de contato.

Palavras-chave: cidade, televisão, espaço público, comunicação, tecnologia
$\mathrm{Na}$ hegemonia dos fluxos e na transversalidade das redes, na heterogeneidade de suas tribos e na proliferação de seus anonimatos, a cidade virtual descortina, por sua vez, o primeiro território sem fronteiras e o lugar onde se avista a sombra ameaçante da contraditória "utopia da comunicação".

Abstract: The article deals with the new mechanisms of sociability in the major cities, most especially in the Latin American ones. Continual flux of vehicles, cultural fragmentation, the young peoples' "tribes", the public space emptied out because of fear and by reclusion in front of the television set, the computer, and the transit ease reached by new technologies make the city ever so much less a encounter territory in order to be a possibility of contact.

Keywords: city, television, public space, communication, technology

48. Eram chamados palimpsestos os pergaminhos cuja escrita fora apagada para receber outro manuscrito. No processo de recomposição das várias camadas de escrita sobrepostas, muitas vezes o reagente químico acabava por danificar para sempre os pergaminhos. Usa-se, hoje, no sentido de uma "camada" textual que vai fazendo desaparecer outras "camadas", num processo de enfumaçamento (N.T.). 